In the Royal Victorian Institute for the blind it figures in very small numbers insignificant as compared with myopia and optic atrophy, etc.

I conclude by quoting Mr. Lawson, who, when I was an Assistant at Moorfields said "If a son of mine got a severe injury to his eye I should pray God that the injury was great enough to hit the issue beyond doubt."

It is a tragedy that with the most capable investigators at work no one can even make an accurate güess at the cause of this fortunately rare tragedy, at all events now-a-days.

It is much like the advice given by Dr. Kellaway regarding snake bite, i.e., "don't get bitten." "We can do something for our Tiger Snake and Black. Snake, but the Brown Snake and the Adder are very deadly.

I have in mind a fine young man who recently received an injury with a piece of metal which penetrated the lens and lodged in the vitreous. The risk was put to him and the delays which treatment would involve. He acted decisively when he understood and said "remove the eye at once." But everyone is not so clear headed.

$$
\text { I am, etc., }
$$

103-105, Collins STReet,

Mel,bourne, C.1

JAMES W. BARRETT.

April 12, 1943.

\title{
SULPHONAMIDES IN EXPERIMENTAL OCULAR INFECTIONS
}

\section{To the Editors of THE BRITISH JOURNAL OF OPHTHALMOLOGY.}

Dear Sirs,-The paper in the Brit. Jl. Ophthal., for June, 1943, by Klein and Sorsby raises certain questions of general interest regarding sulphonamide therapy. In considering the problem of the local and general use of these drugs certain important facts concerning their mode of action should be kept in mind. Up to recent times it has been necessary to regard treatment of infective conditions in terms of antiseptics, such as silver nitrate or argyrol, substances which cannot be given systemically, and general treatment in terms of such drugs as organic arsenicals or salicylates, which have no value as local applications. The discovery of the sulphonamides has made available drugs which produce their effect whatever the method of administration, provided that a suitable concentration be produced at the site of the lesion. General 
herapy may have certain technical advantages such as simplicity of administration, but it also has definite disadvantages. Thus, undesirable toxic effects may arise, and in addition an appreciable number of patients become sensitised to the drugs; this fear of sensitisation, moreover, limits the period of administration by the general route. It is for these reasons, amongst others, that the sulphonamides have been placed on Schedule IV. By the local administration of sulphonamides these disadvantages can be avoided in eye work. Local application has another advantage, in that much higher concentrations of the drug can be produced in the conjunctiva and cornea than by general administration. This is of importance, since there is evidence that these higher concentrations can be more efficacious in the control of certain types of infection. It is, however, undesirable to attempt to produce these high concentrations by the application of a powder, since irritation may be produced. Local application should produce minimal irritant effects, and these may be avoided by using a readily soluble preparation making a solution with a $\mathrm{pH}$ similar to that of the body fluids.

That the local application of sulphonamides can produce chemotherapeutic actions has been shown by work on experimental infection in rabbits (pneumococcus, staphylococcus, pyocyaneus), and by the growing number of clinical observations reported in the literature. Our views on the whole problem may become biassed if we allow the success obtained by oral administration in the treatment of ophthalmia neonatorum to obscure the very real danger of producing sensitisation in adults. The technical difficulty of local administration in the newborn may justify the risk but the routine administration of these substarices by mouth to newborn children would be hard to justify. Local application as a routine prophylactic measure might well be used in place of the present antiseptics in these cases.

Local therapy is, moreover, undoubtedly of value for prophylaxis against infection in cases of injury and is used on a quite large scale in this country at present. General administration would obviously be unpracticable and undesirable.

Our object in writing this letter is to insist that these basic considerations be kept in the minds of ophthalmologists when attempting to translate into clinical terms the observation of the laboratory.

$$
\begin{aligned}
& \text { Yours faithfully, } \\
& \text { W. J. B. RIDDELL, } \\
& \text { J. M. RoBson. }
\end{aligned}
$$

PHARMACOLOGY DEPARTMENT, UNIVERSITY OF EDINBURGH. 